\title{
Effect of A Designed Nursing and Patients Self Care Protocol on Reducing the Colostomy and Peristomal Skin Complications among the Elderly Patients.
}

Marwa Kamal Ahmed 1, Eman Talaat Mohammed 2, Tohamy Abd -Allah Tohamy 3, Jehan Abd El-Rahem Mohammed 4

1. Demonstrator in Medical Surgical Nursing (Gerontological Nursing),Faculty of Nursing-Minia University.

2. Professor \& Head of Medical Surgical Nursing Department, Faculty of Nursing- Ain Shams University.

3. Prof. dr. of General Surgery \&Endoscopies, Faculty of Medicin- Minia University

4. Lecturer of Medical-Surgical Nursing (Gerontological Nursing), Faculty of Nursing - Minia University. *Email of the corresponding author:Marwa_Kamal@yahoo.com

Abstract

Background: Though creation of an ostomy is a life saving procedure and increased lifespan it may result in significant number of complications which impact body image, daily functioning, social activities and a significant reduction in the quality of life. So persons living with colostomy require comprehensive education, training to manage their stoma and to identify, prevent stomal or peristomal complications during the early postoperative period. Aim of the study: To evaluate the effect of a designed nursing and patients self care protocol on reducing the colostomy and peristomal skin complications among the elderly patients. Research design: A Quasi-experimental research design was utilized in the current study. Subjects: A purposive sample including (60) elderly patients from both sexes (males \& females) aged 60yrs old and older were included in the current study, they were classified into two equal groups $(n o=30)$ for the study group and $(n o=30)$ for the control group. Setting: This study was carried out at General Surgical Department and Surgical Outpatient Clinics in Minia University Hospital. Tools of data collection: Four tools were utilized to collect data. Tool I: Patient assessment sheet, Tool II: Designed colostomy nursing and patient's self-care protocol. Tool III: Observation Check list designed by the researcher, Tool IV: Peristomal skin assessment scale. Results: The results of the current study revealed that, the majority of the study group had normal skin along all observations, while all of the control group didn't have normal skin along the 7 observations. Also, there were statistically significant differences among the study and control groups regarding total DET score along the 7 observations. Conclusion: It was concluded that implementation of the educational guideline about stoma self care had a positive effect on improving awareness regarding practice among the study group which leading to prevention of the peristomal skin complications. Also, it was found the majority of study group didn't have peristomal skin complications along all observations while among the control group there was an increase of peristomal skin complications. Recommendations: proper counseling sessions as well as pre and post operative education for ostomy patients that will help them to adjust to their stoma care in a better way. There is need for a simplified illustrated and comprehensive Arabic-language booklet to be used as reference educational guidance for patients with colostomy. In-service educational programs and job training to upgrade nurse's knowledge, attitudes and practices toward providing essentials components of nursing care.

Key Words: Colostomy, Elderly patients, Peristomal skin, Complications, and Self care protocol.

\section{Introduction}

Colostomy is a surgically created opening between the colon and abdominal wall to allow fecal elimination leaving the patient with an opening on the abdomen called stoma in which waste is passed into an appliance that must be emptied periodically. The colostomy may be temporary or permanent diversion, it is named according to where in the bowel it is formed (Campos et al., 2017).

A stoma is a part of the intestine (small or large) that is brought above the abdominal wall to become the outlet for discharge of fecal matter rather than being eliminated through the anus. The most common indication for stoma formation is for decompression, drainage, diversion, and protection of an anastomosis. The major etiological factors are colorectal trauma, intestinal obstruction and carcinoma of colon, ischemia to the small or large intestine (Bennett \& Wick, 2017).

Like any other surgical procedure, colostomy patients face many problems. These problems can be physical or psychological, nutritional problems, bowel problems, sexual, social interaction problems, that interfere with day-to-day living. In addition, other sources of problems include skin irritation and application of pouching system correctly, problems of leakage or presence of bad odor. Additionally, the presence of colostomy itself is considered as a big problem which affects the body image of those patients (Shaffy, Kaur, Das \& Gupta, 2012).

The importance of the role of nursing professional is pointed out in the pursuit of subsidies which favor the planning of the teaching for the stoma patient and his family, as well as their preparation to offer professional support to make the physiological recovery. It is believed that colostomy construction under the care of a colorectal surgeon and stoma nurse would reduce the risk of postoperative complications. Coexistence with the stoma requires that the ostomized person adopt numerous measures of adaptation and readjustment to daily activities, including learning the actions of self-care of the stoma and peristaltic skin. The nurse has an important role in the rehabilitation of the stomized patient since the choice of type of bag, type of skin protector or protective barrier of skin and accessory products to be used, which allows the individual greater independence (Sarabi, Navipour \& Mohammadi, 2017).

Major duties and responsibilities for nursing care include preparing the patient physically for surgery; providing information about pre and post-operative care, including stoma care and supporting the patient and family emotionally. All members of the health care team, including the wound ostomy and continence nurse (WOCN), should be available for assistance, support and visualizing a successful recovery from surgery (Subih \& Teresa, 2016). Specific information is given to patients pre-operatively regarding the practical management of the stoma and to prepare them psychologically for the stoma. Post-operatively, patients will continue to require information and support from everyone involved in their care. After the hospital discharge, the process of living as an intestinal stoma patient begins. This process can be favored with the teaching of individualized 
self-care, the use of devices and the clinical assistance to control of the disease complications, treatment, allowing them to fulfill their family, work and social duties and return to the relationships, activities, hobbies and improving life style is a very important goal in treating and caring for patients with colostomy (Johnson, Readding \& Ryan, 2015).

\section{Significance of the study:}

Peristomal skin problems are significant, affecting one third of colostomy patients. Complications related to the stoma often have a significant reduction in quality of life and lead to social isolation. Various studies have reported a peristomal skin complications rate ranging from $18-60 \%$ (Meisner et al., 2012). Patients aged 70 and older have more fecal ostomy procedures than younger patients, with longer hospital stays, lack of knowledge about stoma self-care, types of appliances, patients are exposed to more postoperative complications and higher mortality rates (Wong, Young, Widder \& Khadaroo, 2013).

\section{Aim of the Study:}

The aim of the study is to evaluate the effect of a designed nursing and patients self care protocol on reducing the colostomy and peristomal skin complications among the elderly patients.

\section{Research hypothesis}

Designed colostomy nursing care protocol will reducing the stoma and peristomal skin complication among the elderly patients.

\section{Subjects and Methods: \\ Research Design:}

Quasi-experimental research design was utilized in the current study.

\section{Setting of the study:}

This study was carried out at General Surgical Department and Surgical Outpatient Clinics in Minia University Hospital.

\section{Study Subjects:}

A purposive sample of 60 elderly patients from both sexes (males \& females) aged 60yrs old and older who are newly admitted to general surgical department in Minia university hospital was classified equally into two groups $(\mathrm{no}=30)$ for the study group and $\left(\mathrm{no}^{-30)}\right.$ ) for the control group. The data from the control group were collected firstly then the data from study group were collected. The study group received the designed colostomy nursing care protocol and the control group did not receive the designed nursing care protocol.

-The sample was selected according to the following criteria:

\section{Inclusion Criteria:}

- All patients admitted to surgical department from surgical outpatient as well as emergency department who underwent surgeries which ended in colostomy.

- Patients 60 years of age and older were included.

- Both sexes (males and females) participated in the study.

- $\quad$ Patients with all types of colostomy.
- Patients with new colostomy.

- Patients free from liver cirrhosis, renal failure and cancer.

\section{Exclusion Criteria:}

- Patients with evidence of acute confusion state or dementia.

- Patients who refused to participate in the study.

- Dependent patients.

\section{Study Tools:}

Four tools were utilized to collect the data pertinent to the current study, these tools were tested by the researcher after pilot study and the content of the tools was established after extensive literature review and were revised by members of a jury who are experts in the field of study.

Tool 1: Patient assessment sheet it was included two main parts:

First part; covered the socio- demographic data of the patient as name, age, gender, marital status, education, and.....etc.

Second part; Covered medical data as: date of admission, medical diagnosis, Patient's health history, presence of any chronic disease.

Tool 2: A designed colostomy nursing and patient's self-care protocol (hand out) was given to the patients. It was written in simple Arabic language and included pictures to show the steps of care.

- It was applied by the researcher to the study group only. The researcher trained the patient and the care giver, demonstrated the steps of stoma and peristomal skin care, steps of hand washing, stoma wound care, emptying and changing stoma pouch, stoma irrigation, peristomal skin care, warning signs and symptom of colostomy complications in the pre-operative phase. researcher.

Tool 3: Observation Check list designed by the

- Observation Check list was applied immediately after teaching and every follow up session to evaluate the patient's performance about the steps of stoma self-care and peristomal skin care.

Tool 4: Peristomal skin assessment scale which consists of three domains: Discoloration, Erosion, and Tissue overgrowth (DET) score

- It is a measuring instrument which was used to assess the extent and severity of peristomal skin complications. The total score is (15) categorized as follows, unaffected $($ DET $=$ zero $)$, mild $($ DET $=1-3)$, moderate $($ DET $=4-6)$, and severe $(\mathrm{DET}=7-15)$.

\section{Tools Validity:}

Tools content validity was done to identify the degree of the used tools which measure what was supposed to be measured. The developed tools were examined by a panel of 3 experts in the field of this study at Minia University - Faculty of Nursing (Medical Surgical Nursing Department). All jury members (100\%) agreed that the current study tools were valid and relevant to the aim of the study.

\section{Tools Reliability:}

Reliability of tools was tested by using Cronbach's Alpha test and it was from 0.65-0.99. 


\section{Pilot study:}

A pilot study was carried out on 6 patients $(10 \%)$ of the total sample in July 2016 to test feasibility, objectivity, and applicability of the tools. Results of the pilot study illustrated that no any refinements and modifications needed so the subjects were included to the actual sample.

Procedure for designed colostomy nursing and patient's self-care protocol.

The current study was conducted by preparing of different data collection tools. The total data collections were collected over a period of 12 months starting from 10th September 2016 until 18th October 2017. The collection of study data was on daily basis during morning shift in surgical outpatient clinic before admission to surgical department to select cases that relevant with this study. The sample that was selected informed individually about purpose and nature of the study in their rooms in surgical ward, and then the researcher obtained consent from those who accepted to participate in this study. The researcher started data collection with the control group firstly included
30 patients who received routine hospital nursing care without provided any teaching process from the researcher and the researcher just assessed and observed the patient's performance about stoma and peristomal skin care. Each patient received one session daily ranged from 20 to 30 minutes for session, just observation for they practice.

On the other hand the study group received one session daily which ranged from (45to55) minutes because they performed training and educational practices individually in the form of small teaching and practical sessions.

The researcher was followed the patients by telephone daily after discharged from the hospital to ensure that the patient follow application of procedure and for providing necessary care and presence of any symptoms of stoma abnormalities. (The researcher was offered the prescribed medications which prescribed by physician and the researcher was offered equipment for the patient to enhanced attendance and continuity of care).

\section{Results}

Table (1) Socio demographic characteristics of study \& control groups $(n=60)$.

\begin{tabular}{|c|c|c|c|c|}
\hline \multirow[t]{3}{*}{ Socio demographic data } & \multicolumn{4}{|c|}{ Groups } \\
\hline & \multicolumn{2}{|c|}{ Study $(n=30)$} & \multicolumn{2}{|c|}{ Control(n=30) } \\
\hline & No & $\%$ & No & $\%$ \\
\hline \multicolumn{5}{|l|}{ Age/years } \\
\hline 60to less than 65years & 17 & $56.7 \%$ & 11 & $36.7 \%$ \\
\hline 65 to less than 70 years & 8 & $26.7 \%$ & 10 & $33.3 \%$ \\
\hline 70years and above & 5 & $16.7 \%$ & 9 & $30 \%$ \\
\hline \multicolumn{5}{|l|}{ Gender } \\
\hline Male & 19 & $63.3 \%$ & 20 & $66.7 \%$ \\
\hline Female & 11 & $36.7 \%$ & 10 & $33.3 \%$ \\
\hline \multicolumn{5}{|l|}{ Marital status } \\
\hline Single & 3 & $10 \%$ & 7 & $23.3 \%$ \\
\hline Married & 21 & $70 \%$ & 14 & $46.7 \%$ \\
\hline Divorced & 6 & $20 \%$ & 9 & $30 \%$ \\
\hline \multicolumn{5}{|l|}{ Occupation } \\
\hline Farmer & 10 & $33.3 \%$ & 14 & $46.7 \%$ \\
\hline Retired & 6 & $20 \%$ & 3 & $10 \%$ \\
\hline House wife & 6 & $20 \%$ & 4 & $13.3 \%$ \\
\hline Un employed & 7 & $23.3 \%$ & 6 & $20 \%$ \\
\hline Others & 1 & $3.3 \%$ & 3 & $10 \%$ \\
\hline \multicolumn{5}{|l|}{ Education } \\
\hline Illiterate & 14 & $46.7 \%$ & 18 & $60 \%$ \\
\hline Read and write & 5 & $16.7 \%$ & 9 & $30 \%$ \\
\hline Primary & 4 & $13.3 \%$ & 1 & $3.3 \%$ \\
\hline Secondary & 2 & $6.7 \%$ & 0 & 0 \\
\hline University & 5 & $16.7 \%$ & 2 & $6.7 \%$ \\
\hline \multicolumn{5}{|l|}{ Residence } \\
\hline Urban & 14 & $46.7 \%$ & 10 & $33.3 \%$ \\
\hline Rural & 16 & $53.3 \%$ & 20 & $66.7 \%$ \\
\hline \multicolumn{5}{|l|}{ Availability of assistant relative } \\
\hline Yes & 30 & $100 \%$ & 30 & $100 \%$ \\
\hline No & 0 & 0 & 0 & 0 \\
\hline
\end{tabular}

Table (1): Illustrates, the percentage of the distribution of the study and control groups as regards socio demographic characteristics, it shows that the highest percentage of the sample is in the age group (60 to 65) years old, (56.7\%) in the study group and (36.7\%) in the control group, and more than two thirds were males, the study group (63.3\%) and the control group $(66.7 \%)$. As regards marital status for both groups, the highest percentages in the two groups were married, the study group (70\%) and the control $(46.7 \%)$ respectively. On the other hand, most of the study sampls were farmers, the study group (33.3\%) and the 
Minia Scientific Nursing Journal (Print) (ISSN 2537-012X) Vol. (4) No. (1) December 2018

control group (46.7\%). As related to their educational level in the two groups, there is more than half of the control group were illiterate $(60 \%)$, and the study group (46.7\%), and most of the study sample lived in rural area. All of both groups had assistant relatives with a percentage of $(100 \%)$.

Table (2): Percentage distribution of the studied groups as regards their medical information data $(n=60)$.

\begin{tabular}{|c|c|c|c|c|}
\hline \multirow{3}{*}{ Medical Data } & \multicolumn{4}{|c|}{ Groups } \\
\hline & \multicolumn{2}{|c|}{$\operatorname{Study}(\mathrm{n}=30)$} & \multicolumn{2}{|c|}{ Control $(n=30)$} \\
\hline & No & $\%$ & No & $\%$ \\
\hline \multicolumn{5}{|l|}{ Type of operation } \\
\hline Ascending colostomy & 3 & $10 \%$ & 5 & $16.7 \%$ \\
\hline Transverse colostomy & 9 & $30 \%$ & 9 & $30 \%$ \\
\hline Descending or sigmoid colostomy & 18 & $60 \%$ & 16 & $53.3 \%$ \\
\hline \multicolumn{5}{|l|}{ Indication of surgery } \\
\hline Trauma to abdominal wall & 7 & $23.3 \%$ & 5 & $16.7 \%$ \\
\hline Intestinal obstruction & 22 & $73.3 \%$ & 22 & $73.3 \%$ \\
\hline Inflammatory bowel disease & 1 & $3.3 \%$ & 3 & $10 \%$ \\
\hline \multicolumn{5}{|l|}{ Smoking } \\
\hline Yes & 13 & $43.3 \%$ & 13 & $43.3 \%$ \\
\hline No & 17 & $56.7 \%$ & 17 & $56.7 \%$ \\
\hline \multicolumn{5}{|l|}{ Previous abdominal surgery } \\
\hline Yes & 4 & $13.3 \%$ & 2 & $6.7 \%$ \\
\hline No & 26 & $66.7 \%$ & 28 & $93.3 \%$ \\
\hline
\end{tabular}

Table (2): shows the percentage distribution of the study sample, as regards medical data for the study and the control groups. According to the type of operation for both groups, results represents that more than half of them were descending colostomy, the study group (60\%), and the control group (53.3\%), respectively while the lowest percentage had ascending colostomy, (10\% for the study group\& $16.7 \%$ for the control group). As regards indication of surgery, most of them were due to intestinal obstruction with equal percentage of (73.3\%) for both groups (the study group \& control group). More than half of the study group and control group were none smokers with percentage of (56.7\%), according to previous abdominal surgery, most of them for both groups had no abdominal surgery, the study group (66.7\%), and control group (93.3\%).

\section{Figure (1): Score distribution of Discoloration in the 7th observation for the study and control groups.}

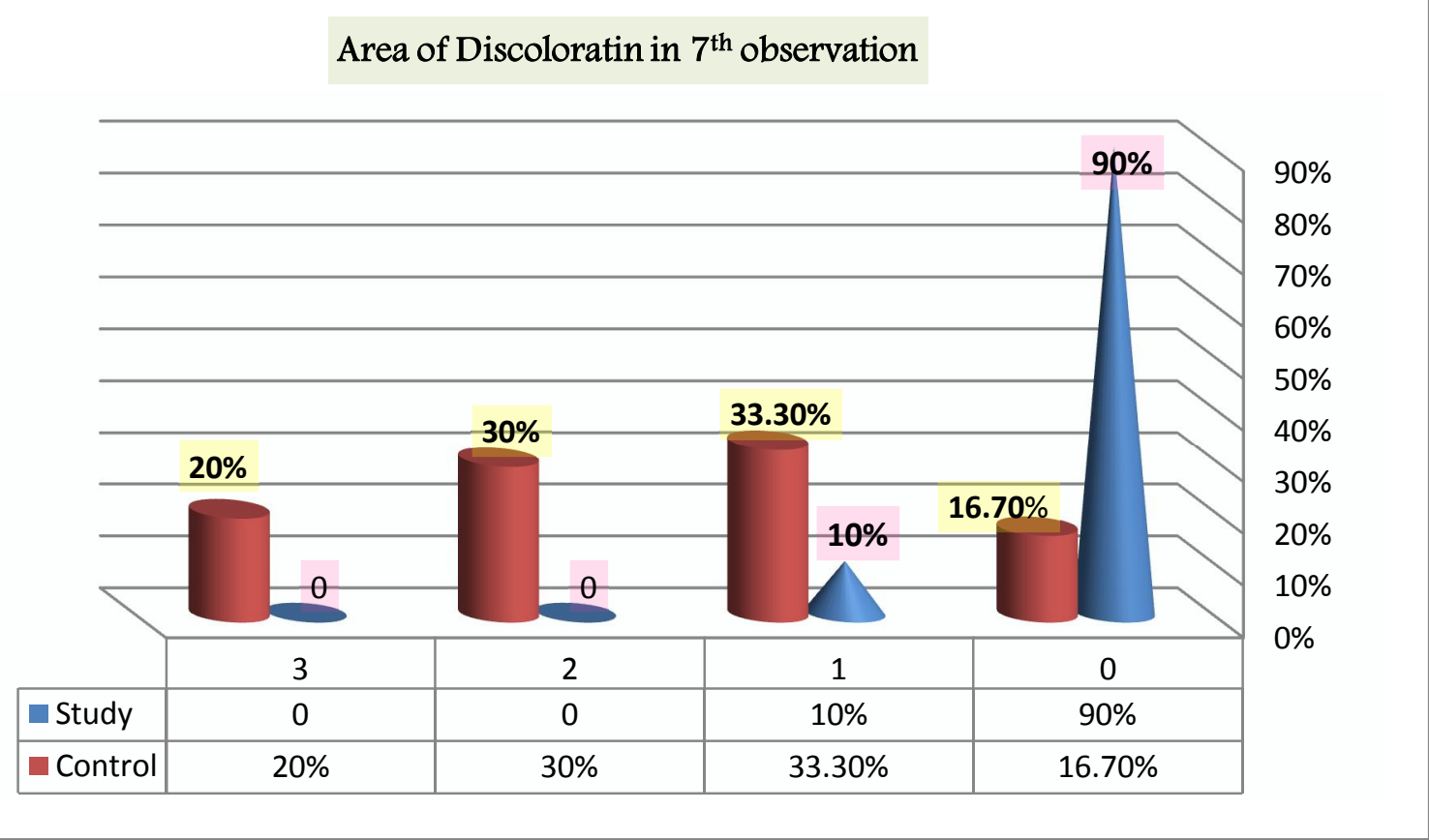

Figure (1): Illustrates that (90\%) of the study group didn't have Discoloration of the skin, while (33.3\%) of the control group had score (1) in area. 
Minia Scientific Nursing Journal (Print) (ISSN 2537-012X) Vol. (4) No. (1) December 2018

Figure (2): Score distribution of Erosion in the 7th observation for the study and control groups.

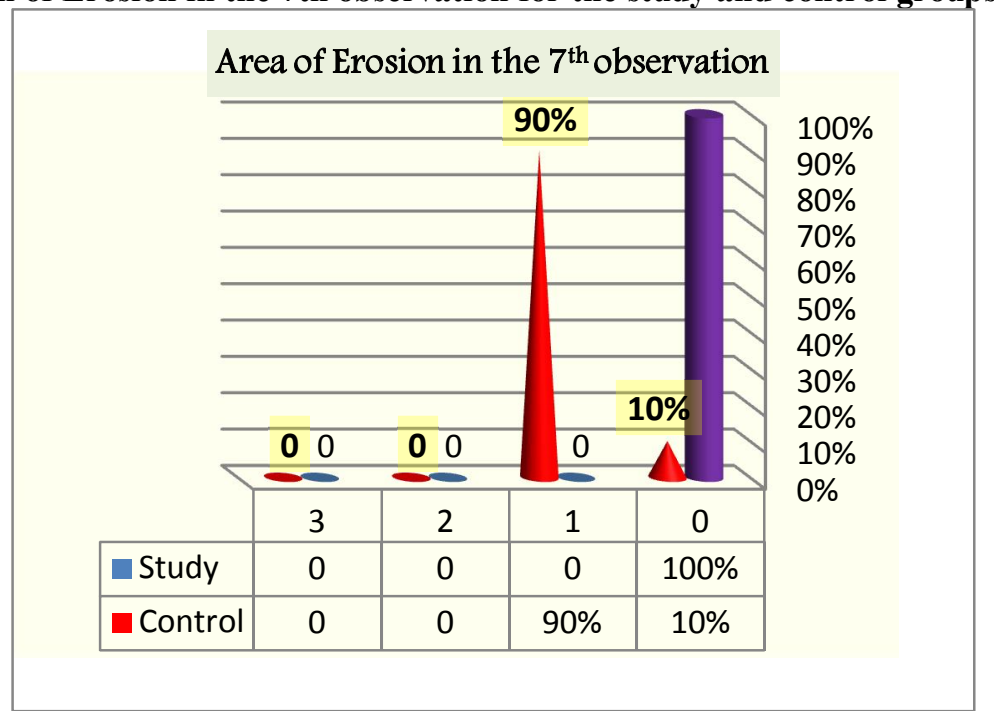

Figure (2): Revealed that (100\%) of the study group patients didn't have Erosion of the skin, while (90\%) of the control group had score (1) in area.

Figure (3): Score distribution of Tissue overgrowth in the 7th observation for the study and control groups.

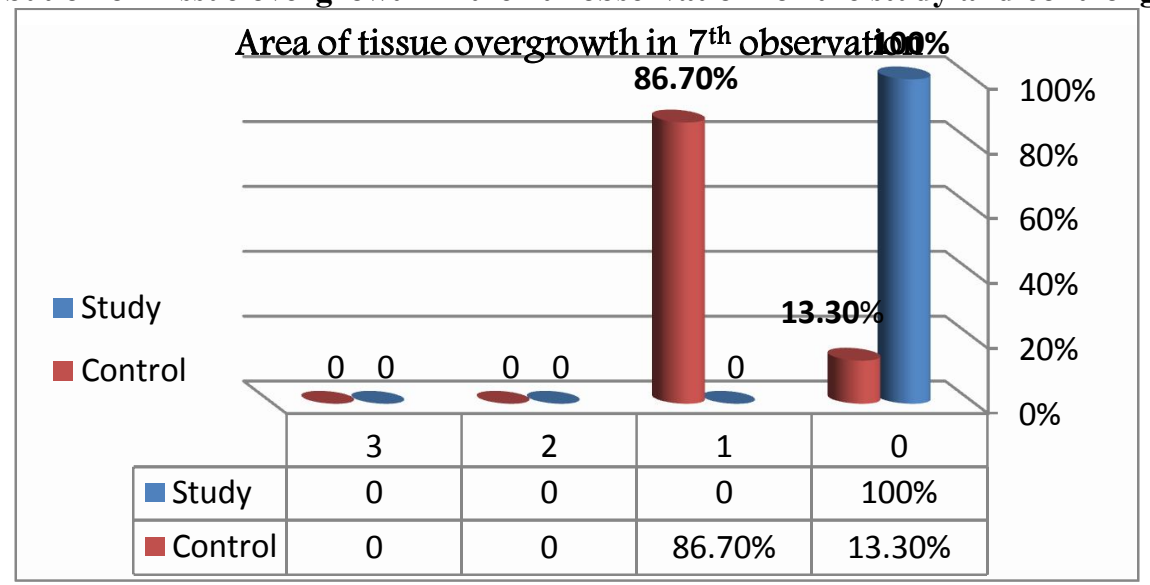

Figure (3): Revealed that (100\%) of the study group patients didn't have Tissue overgrowth, while (86.7\%) of the control group had score (1) in area.

Figure (4): Distribution of total DET in the 6th observation for the study and control groups.

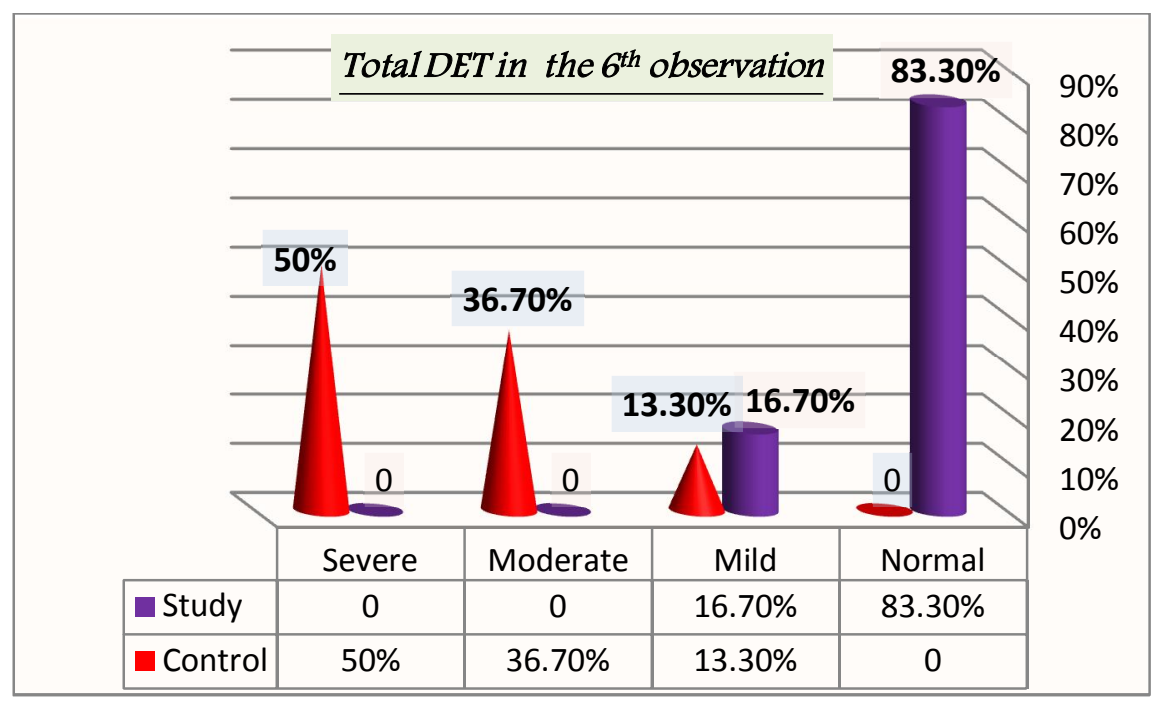

Figure (4): Illustrates that (83.3\%) of the study group had normal skin and (100\%) of them didn't have any moderate and severe complications, while $(13.3 \%)$ of the control group had mild complications, $(36.7 \%)$ had moderate complications, and $(50 \%)$ of the same group had severe complications. 


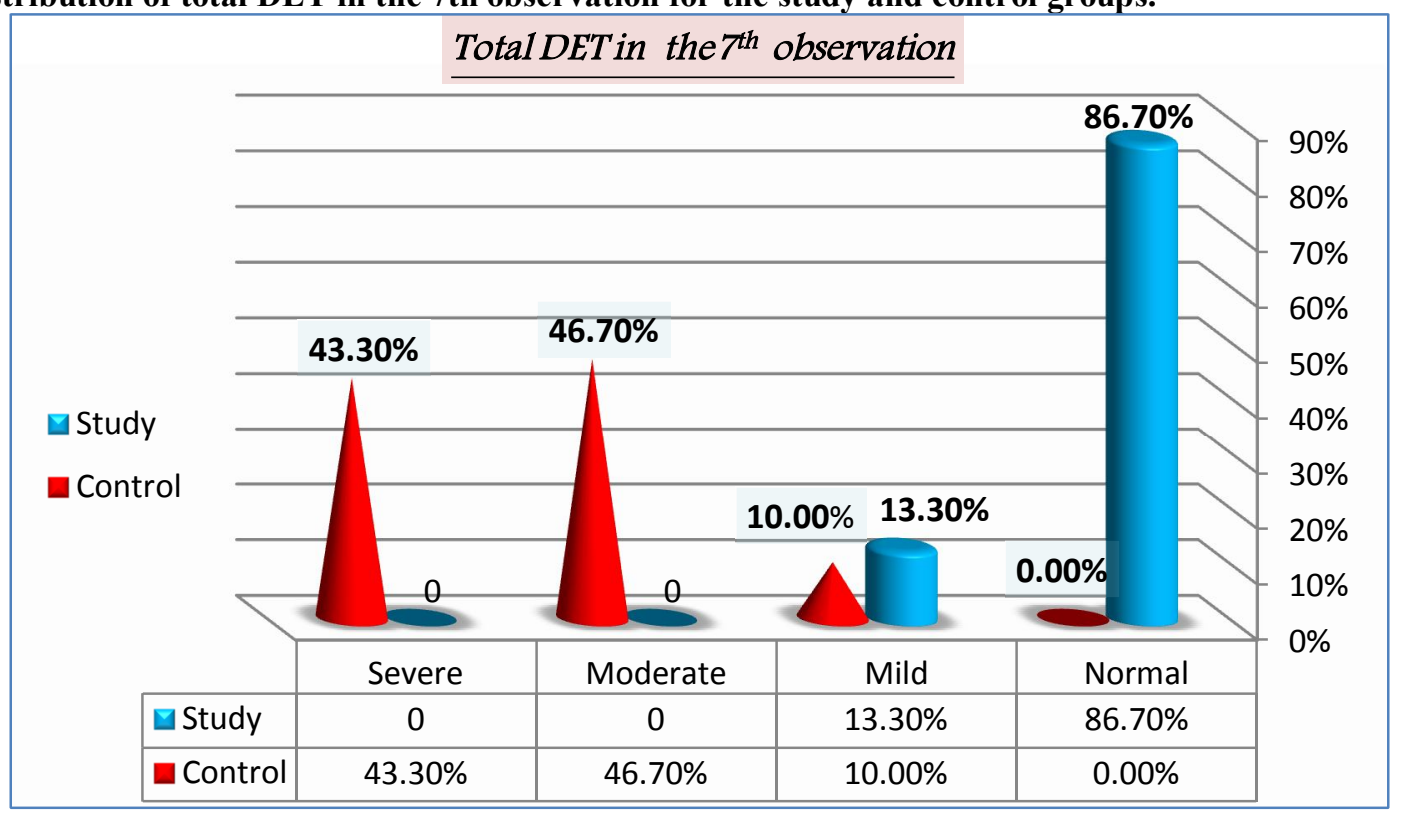

Figure (5): Illustrates that (86.7\%) of the study group had normal skin and (100\%) of them didn't have any moderate and severe complications, while $(100 \%)$ of the control group didn't have normal skin regarding total DET during the 7 th observation, $(46.7 \%)$ of them had moderate complications, and (43.3\%) of the same group had severe complications.

Table (3): Correlation between socio demographic data and procedure score among study group.

\begin{tabular}{|c|c|c|c|c|c|c|c|c|}
\hline \multirow[t]{2}{*}{$\begin{array}{l}\text { Socio } \\
\text { demographic } \\
\text { data }\end{array}$} & $\begin{array}{l}\text { Hand } \\
\text { washing }\end{array}$ & Gloving & $\begin{array}{l}\text { Removing } \\
\text { old pouch }\end{array}$ & $\begin{array}{l}\text { Care of } \\
\text { reusable } \\
\text { pouch }\end{array}$ & $\begin{array}{l}\text { Applying } \\
\text { new } \\
\text { pouch }\end{array}$ & $\begin{array}{l}\text { Stoma } \\
\text { wound } \\
\text { care }\end{array}$ & $\begin{array}{l}\text { Peri } \\
\text { Stoma } \\
\text { skin care }\end{array}$ & $\begin{array}{l}\text { Irrigation } \\
\text { of } \\
\text { colostomy }\end{array}$ \\
\hline & $\mathrm{r}(\mathrm{p})$ & $\mathrm{r}(\mathrm{p})$ & $\mathrm{r}(\mathrm{p})$ & $\mathrm{r}(\mathrm{p})$ & $\mathrm{r}(\mathrm{p})$ & $\mathrm{r}(\mathrm{p})$ & $\mathrm{r}(\mathrm{p})$ & $\mathrm{r}(\mathrm{p})$ \\
\hline Age & $\begin{array}{l}- \\
0.14(0.3)\end{array}$ & $\begin{array}{l}- \\
0.05(0.7)\end{array}$ & $-0.26(0.1)$ & $0.31\left(0.04^{*}\right)$ & $-0.16(0.2)$ & $0.05(0.7)$ & $0.20(0.2)$ & $0.25(0.09)$ \\
\hline Gender & $\begin{array}{l}- \\
0.05(0.7)\end{array}$ & $\begin{array}{l}- \\
0.17(0.2)\end{array}$ & $-0.08(0.6)$ & $-0.03(0.4)$ & $0.02(0.8)$ & $\begin{array}{l}- \\
0.16(0.3)\end{array}$ & $0.01(0.9)$ & $\begin{array}{l}- \\
0.19(0.2)\end{array}$ \\
\hline $\begin{array}{l}\text { Marital } \\
\text { status }\end{array}$ & $\begin{array}{l}- \\
0.10(0.5)\end{array}$ & $\begin{array}{l}- \\
0.15(0.3)\end{array}$ & $0.30(0.07)$ & $-0.34\left(0.03^{*}\right)$ & $0.20(0.1)$ & $\overline{0}-20(0.1)$ & $\begin{array}{l}- \\
0.18(0.2)\end{array}$ & $-0.02(0.9)$ \\
\hline Occupation & $\begin{array}{l}- \\
0.05(0.7)\end{array}$ & $0.02(08)$ & $-0.05(0.7)$ & $-0.07(0.6)$ & $0.13(0.3)$ & $\begin{array}{l}- \\
0.06(0.6)\end{array}$ & $0.17(0.2)$ & $-0.06(0.6)$ \\
\hline Education & $\begin{array}{l}- \\
0.05(0.7)\end{array}$ & $0.03(0.8)$ & $0.31(0.04 *)$ & $-0.06(0.6)$ & $0.14(0.3)$ & $0.20(0.1)$ & $\begin{array}{l}- \\
0.01(0.9)\end{array}$ & $0.10(0.4)$ \\
\hline Residence & $\begin{array}{l}- \\
0.01(0.9)\end{array}$ & $\begin{array}{l}- \\
0.04(0.7)\end{array}$ & $0.10(0.5)$ & $0.15(0.3)$ & $\begin{array}{l}- \\
0.21(0.1)\end{array}$ & $\begin{array}{l}- \\
0.01(0.8)\end{array}$ & $0.07(0.6)$ & $-0.02(0.8)$ \\
\hline
\end{tabular}

Table (3): Regarding the study group, this table shows that there was no statistically significant correlation between sociodemographic data and procedure except a positive correlation was found between age and care of reusable pouch. Also, there was a positive correlation between level of education and removing old pouch. It a negative correlation between marital status and care of reusable pouch was also found.

\section{Discussion}

The present study revealed that colostomy occurred more frequently at the age of 60 . More than half of the study group, and more than a third of the control group. This result was supported by Madick (2011) who carried out a study about "Perioperative care of the patient with Zenker's diverticulum" and found that most respondents (97\%) of colostomy occurred more frequently at the age of 50 years. Also, another research agrees with the current finding by Ahmad, Sharma, Saxena, Choudhary\& Ahmed (2017) who mentioned in their study that titled "A clinical study of intestinal stomas: its indications and complications " that indications for commonly performed intestinal stomas occurred with the mean age $50.5 \pm 29.01$ years with a range of 12 to 85 years.

Regarding sex, the results of the current study revealed that more than half of the patients in both groups were males. This result is in the same line with the study by Salomé \& Almeida (2014) whose study was about "Association of socio-demographic and clinical factors with 
the self-image and self-esteem of individuals with intestinal stoma". It was reported that the majority of subjects with intestinal stoma (74.3\%) were males. In the same line Mohey El Din, et al. (2014) reported that more than three fifths of the studied subjects were males, and two fifths of the studied subjects had secondary education.

As regards to marital status, the majority of the study patients were married, whereas, the minority of them were single for both groups. This result is in agreement with Wang (2018) who conducted in a study about" Investigation and analysis for impact factors of psychological distress in rectal cancer patients with a permanent colostomy". The researcher stated that most of the rectal cancer patients with permanent colostomy were married with a percentage of $(93.4 \%)$.

The results of the current study revealed that the main indication for colostomy formation for both groups was intestinal obstruction followed by trauma to abdominal wall, and this result is similar to Ahmad, Saeed, Muneera, Ahmed \& Khalid (2010) who mentioned in their study about" Indications and complications of intestinal stomas" that $(50.87 \%)$ of colostomies formation was due to obstruction followed by penetrating injury (33.3\%). Another study disagrees with the current finding by Engida, Ayelign, Mahteme, Aida \& Abreham (2016) whose study was about "Types and indications of colostomy and determinants of outcomes of patients after surgery". They mentioned that the indications for colostomy formation were $(46.6 \%)$ due to gangrenous sigmoid volvulus, $(21 \%)$ for colorectal cancers, and $(12.8 \%)$ for abdominal injuries.

Regarding occurrence of Discoloration, Erosion, and Tissue overgrowth, the results of the current study revealed that the majority of the study group had normal peristomal skin and all of them didn't have any Erosion or Tissue overgrowth, while the control group had about three fourth of discoloration during the 2nd observation, highest percentage of erosion Erosion and tissue over growth during the 7 th observation due to lack of peristomal care. These results are in the same line with Alenezi \& Mansour (2016) who reported in their study about" Impact of Stoma Care Education in Minimizing the Incidence of Stoma Skin Complications" that among the study group, there were a decrease in peristomal skin complications and significant increase of stoma skin complications in the control group with statistically significant difference between both groups regarding skin assessment around the stoma six weeks postoperatively. In the first week postoperative, the study group had normal intact peristomal area and the control group developed hyperemic lesion. Also, during week three postoperative, $(46 \%)$ of the control group had hyperemic lesions and $(50 \%)$ of them had Erosive lesion. In week six postoperative $(30 \%)$ of the control group developed hyperemic lesions around the stoma, (48\%) of them had Erosive lesions, while (100\%) didn't have Erosion or ulcerative lesion in the study group $(\mathrm{P}<0.005)$.

Regarding to total DET, the results of the present study showed that all of subjects in the control group had mild, moderate and severe peristomal complications with two thirds of them had mild complication in the $3 \mathrm{rd}$ observation and also two thirds of the control group had moderate complication in the 4 th $\& 5$ th observations, and half of them had severe complication found during the 6th observation due to ignorance on how to perform complete stoma self care which led to leakage of feces at peristomal $P$ a g e $\mid 74$ skin area. These results agree with Herlufsen, et al. (2006) who reported in their study about "Study of peristomal skin disorders in patients with permanent stomas" that the majority of patients with skin disorder were classified as $(65 \%)$ mild peristomal complications, $(29 \%)$ of moderate skin disorders and $(6 \%)$ severe. He mentioned that those patients who did not receive education and regular follow up visits at stoma care clinics to ensure optimal peristomal skin health, with the absence of education about self care, the patients ignored to clean their peristomal skin well and skin might have been left exposed to stoma effluent for up to several days depending on the wear time of the appliance.

The results of the current study revealed that the majority of the study group didn't have peristomal skin complications because of the majority of their applied practice of self-care perfectly except that the minority of them had slightly discoloration during the 3rd and the 6th observations which decreased with continuous management. These findings are consistent with De Sousa et al. (2016) who reported in their study about "Socio demographic and clinical features and quality of life in stomized patients" that the majority of the studied patients did not present postcolostomy complications, and only (10\%) reported dermatitis. This may suggest that self-care or family care management of colostomy patients was adequate and the surgery was successful.

The results of the current study revealed that, among the study group there had been a positive correlation between level of education and removing old pouch.From the researcher's point of view the educated patient understood steps of care and had ability to apply them correctly. These results agreed with de Sousa, et al. (2016) who mentioned that half of the studied patients had education up to primary school. Schooling is a relevant aspect for understanding the educational guidelines of care for stoma, for using the device correctly for waste collection, and for the regular monitoring of health and hygiene.

The current study revealed that among study group there is a positive correlation between gender and DET. From the researcher's point of view, gender influences the adaptation which means that women had a role to manage their own life than men. Females are also more capable of performing self-care activities which aided in reducing stoma related complications. Cheng, Meng, Yang \& Zhang (2013) in their study on "The correlation between ostomy knowledge and self-care ability with psychosocial adjustment in Chinese patients with a permanent colostomy" emphasized that the gender influence the quality of life. Women tend to pay more attention to their appearance than men and are more proactive in stoma care.

\section{Conclusion:}

In the light of current study, it was concluded that, implementation of the educational guideline about stoma self care had a positive effect on improving awareness regarding practice among the study group which leading to significant improvement in all items of self care practices and prevention of the peristomal skin complications.

\section{Recommendations:}

- In-service educational programs and job training to upgrade nurse's knowledge, attitudes and practices toward providing essential components of nursing care which include patients with colostomy and assess the patient for detecting the problems.

Marwa K., et al 
- Providing knowledge and teaching self-care instruction before hospital discharge given by the nurse for the patients regarding complications prevention and health promotion after stoma surgery may improve quality of life.

\section{References}

1. Ahmad, Q. A., Saeed, M. K., Muneera, M. J., Ahmed, M. S., \& Khalid, K. (2010). Indications and complications of intestinal stomas-A tertiary care hospital experience. Biomedica, 26(2), 144-147.

2. Ahmad, Z., Sharma, A., Saxena, P., Choudhary, A., \& Ahmed, M. (2017). A clinical study of intestinal stomas: its indications and complications. International Journal of Research in Medical Sciences, 1(4), 536-540.

3. Alenezi, A. N., \& Mansour, E. A. (2016). Impact of Stoma Care Education in Minimizing the Incidence of Stoma Skin Complications. Bahrain Medical Bulletin, 38(3).

4. Bennett, J. L., \& Wick, E. C. (2017). Fecal Diversion and Ostomies. In Pelvic Floor Dysfunction and Pelvic Surgery in the Elderly (pp. 349-360). Springer, New York, NY.

5. Campos, K. D., Bot, L. H. B., Petroianu, A., Rebelo, P. A., Souza, A. A. C. D., \& Panhoca, I. (2017). The impact of colostomy on the patient's life. Journal of Coloproctology (Rio de Janeiro), 37(3), 205-210.

6. de Sousa, M. J., da Costa Andrade, S. S., de Brito, K. K. G., de Oliveira Matos, S. D., Coêlho, H. F. C., \& dos Santos Oliveira, S. H. (2016). Sociodemographic and clinical features and quality of life in stomized patients. Journal of Coloproctology, 36(1), 27-33.

7. Engida, A., Ayelign, T., Mahteme, B., Aida, T., \& Abreham, B. (2016). Types and indications of colostomy and determinants of outcomes of patients after surgery. Ethiopian journal of health sciences, 26(2), 117122.

8. Herlufsen, P., Olsen, A. G., Carlsen, B., Nybaek, H., Jemec, G. B., Karlsmark, T., \& Laursen, T. N. (2006). Study of peristomal skin disorders in patients with permanent stomas. British Journal of Nursing, 15(16), 854862.
9. Johnson, D., Readding, L., \& Ryan, C. (2015). Analysing the role of support wear, clothing and accessories in maintaining ostomates' quality of life. Gastrointestinal Nursing, 13(7), 23-35.

10. Madick, S. (2011). Perioperative care of the patient with Zenker's diverticulum. AORN Journal, 73(5):904- 13. https://doi.org/10.1016/S0001-2092(06)61742-0

11. Meisner, S., Lehur, P. A., Moran, B., Martins, L., \& Jemec, G. B. E. (2012). Peristomal skin complications are common, expensive, and difficult to manage: a population based cost modeling study. PLoS One, 7(5), e37813.

12. Mohey El Din, M. A., Hasan, S.A., Abdel Hameed, H.S. \& Abdel Aziz, M. S. (2014). Impact of Health Education Intervention for Colostomy Patients on their Quality of Life at Benha, thesis of doctora degree in nursing, faculty of nursing, Benha Universty, American Journal of Nursing Research, pp 98.

13. Salomé, G. M., \& Almeida, S. A. D. (2014). Association of sociodemographic and clinical factors with the self-image and self-esteem of individuals with intestinal stoma. Journal of Coloproctology (Rio de Janeiro), 34(3), 159-166.

14. Sarabi, N., Navipour, H., \& Mohammadi, E. (2017). Relative Tranquility in Ostomy Patients Social Life: A Qualitative Content Analysis. World journal of surgery, 41(8), 2136-2142.

15. Shaffy, S., Kaur, S., Das, K., \& Gupta, R. (2012). Physical, nutritional and sexual problems experienced by the patients with colostomy/ileostomy: a qualitative study. Nursing and Midwifery Research Journal, 8(3), 210-22.

16. Subih, M. M., \& Teresa, M. O. (2016). Ostomy Educational Program for Nurses in Jordan. Wound Clinic Business.

17. Wang, X. (2018). Investigation and analysis for impact factors of psychological distress in rectal cancer patients with a permanent colostomy.

18. Wong, S. K., Young, P. Y., Widder, S., \& Khadaroo, R. G. (2013). A descriptive survey study on the effect of age on quality of life following stoma surgery. Ostomy Wound Manage, 59(12), 16-23. 